\title{
Aggregate Recycling in Construction: Analysis of the Gaps between the Chilean and Spanish Realities
}

\author{
Marcos Díaz ${ }^{1}$, María Belén Almendro-Candel ${ }^{2}$, David Blanco ${ }^{1}[$ \\ and Manuel Miguel Jordan 2,*(D) \\ 1 Department of Construction Sciences, Metropolitan Technological University, Dieciocho 390, \\ 8330526 Santiago, Chile \\ 2 Department of Agrochemistry and Environment, Miguel Hernández University of Elche, Avd. Universidad \\ s/n, 03202 Elche (Alicante), Spain \\ * Correspondence: manuel.jordan@umh.es
}

Received: 2 May 2019; Accepted: 20 June 2019; Published: 26 June 2019

\begin{abstract}
This study conducts a comparative analysis between Chilean and Spanish reality in regard to the recycling of aggregates and their reuse in road works and urban roads. The current situation of both countries was reviewed through different sources of information such as technical and legal regulation, projects and executed works, to then validate them in Chile by way of interviews to various professionals in the field of urban and interurban road construction, as well as others belonging to government bodies. Spain has extensive experience on this issue, as it has a culture of recycling and reusing aggregates that has produced excellent results, a situation which was taken into account to compare it to Chile's reality. The conclusion is that currently, in Chile, although the existence of recycled aggregate use is known, this is not the case on a technical level for professionals in the sector. It lacks a specific government body that is in charge of this issue and does not have appropriate infrastructure for its treatment. The materials with a promising future within the construction sector are the production of crushed granular bases and the creation of low-resistance concretes, which cannot be used, as laws that regulate them are still being drafted.
\end{abstract}

Keywords: recycled aggregate; sustainability; urban road works

\section{Introduction}

In Chile, the construction industry (in infrastructure works such as building), has significantly increased its activity. Even though this reflects an increase in the development of the country, bringing greater labour opportunities and leading to numerous social benefits, it implies a high number of demolitions, and therefore, a greater amount of waste and residue that is taken to dumping sites.

On the other hand, although Chile has been characterised by being a country rich with natural resources, especially aggregate, evidence is starting to appear of symptoms of shortage of this stone material in some parts of the country, and there has also been an increase in warnings on behalf of some environmentalist groups on the irreversible damage that can be caused to the ecosystem if this material is continued to be extracted in a persistent and uncontrolled way. It is also important to consider the major negative impact that producing concrete, and specifically its components (such as cement), has on the environment, which directly increases the carbon footprint. 
This crisis was already experienced in Spain and numerous European countries several years ago. This is why they have been continuously developing and perfecting aggregate recycling techniques for a significant amount of time. Likewise, they have also focused on creating a suitable framework to be able to promote this activity. As a result, they have developed studies on waste from construction and demolition works (to look into its applicability as a construction material) and have implemented various laws and technical regulations (in order to view recycled aggregate from this type of waste as simply another material, adding it to those that already exist).

In this context, it seems relevant to study the recycling of aggregates as an alternative for applying sustainability to the construction sector in Chile, specifically as it pertains to urban and interurban roads, as large amounts of waste with great reuse potential are generated in these types of projects. To do so, the Chilean reality on this issue must be reviewed, in order to do the same in Spain, then establish a standard for comparison, and finally measure the existing gaps between both countries with regards to the use of recycled aggregates.

Spain was chosen as a reference in this study because it is a country that is very close to the Chilean reality, and it is feasible to determine its context. Its recycling methodology was successful. For these purposes, it is necessary to review the Chilean reality on this issue (regulation, expert opinions), to then do the same with the mentioned European country, in order to establish a standard of comparison and measure the existing gaps among both with regards to the use of recycled aggregates.

\section{Research Programme}

The research methodology was divided in three phases: The first consists of reviewing Chilean reality regarding the recycling of aggregates by taking an in-depth look at various sources of information, such as technical and legal regulation or previous theses, among others. The second phase entails reviewing the reality of aggregate recycling in Spain. This includes the technical and legal regulation, projects and conducted works, among other sources. The last phase consists of validating the previously conducted review of Chilean reality by interviewing various professionals in the field of construction, specifically those from construction companies with experience in the construction of urban and interurban roads, as well as professionals from the Ministry of Public Works (The Ministry in charge of designing, tendering, overseeing and exploiting infrastructure works (Chile)), the Housing and Town Planning Service (SERVIU in Spanish) (Body that is directly dependant of the Ministry of Housing and Urban Development, born from the merging of 4 bodies: Property, urban improvement, housing and urban works (Chile)) and the National Roads Laboratory (Technical body whose purpose is to technically lead and support quality control work related to the execution of road works (Chile)) with the goal of making the perception that exists in the sector known. With the obtained information, both realities are analysed, showing the existing gaps between both countries regarding the recycling of stone materials, supplemented with the technical opinion of the experts interviewed and the feasibility of implementing their knowledge on this issue (Figure 1). 


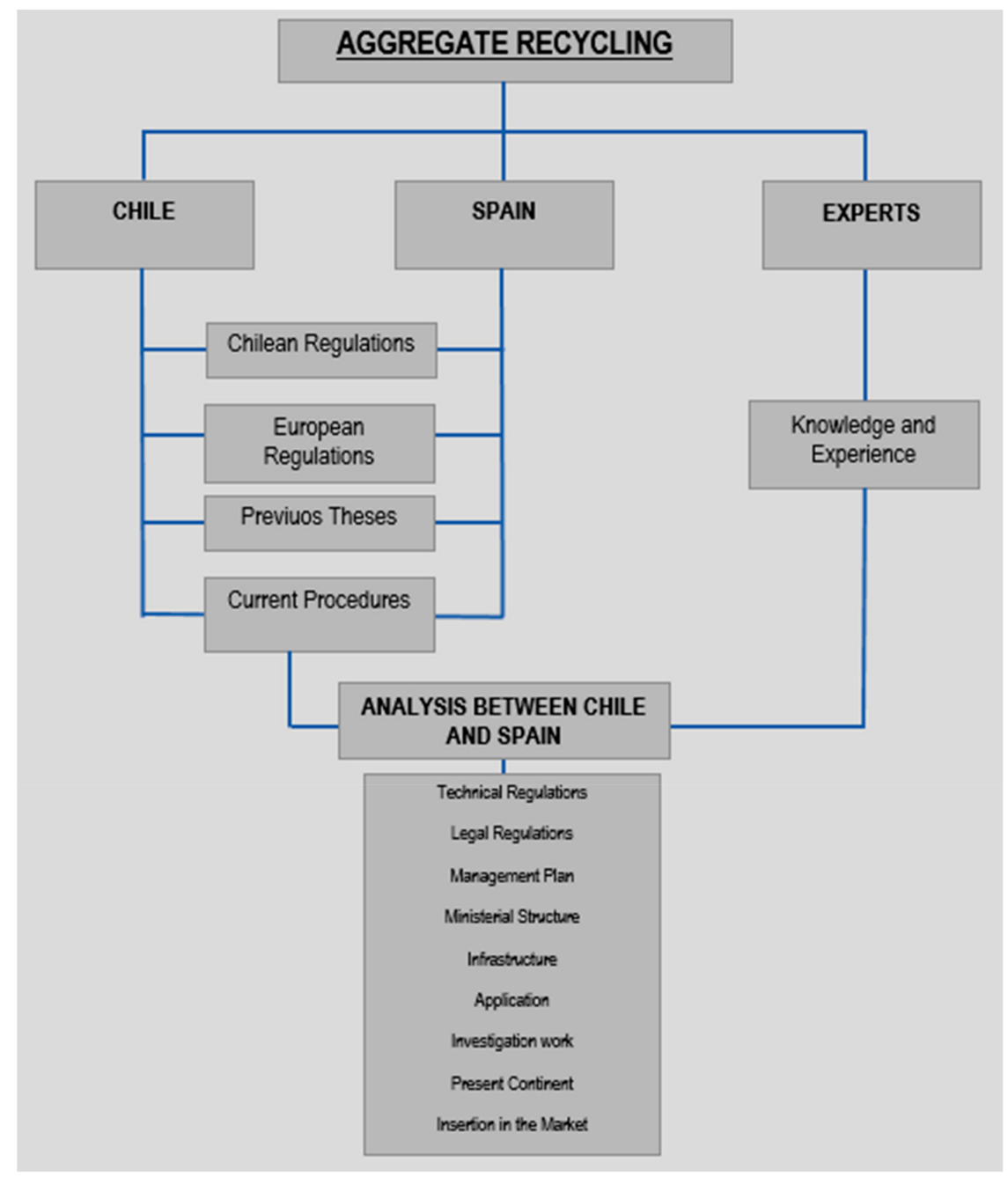

Figure 1. Research methodology.

\section{Results and Discussion}

This section summarises the contents of some of the laws that comprise the regulatory framework applicable to the Construction and Demolition Waste (CDW) in Spain.

\subsection{Spanish Reality}

\subsubsection{Article 45-Spanish Constitution}

The constitution is considered the fundamental law for the organising of any State. This is why it is mentioned in first place on this list. This Article, located in Chapter Three, called "Guiding principles of social and economic policy", referring to the environment and quality of life, establishes the following: That all people have the right to enjoy an environment which is suitable for their development, as well as the duty to preserve it. Furthermore, it establishes the duty that public powers have to monitor the rational use of all natural resources in order to protect and improve quality of life, and to defend and restore the environment, leaning on the essential collective solidarity. Lastly, it decrees the penalties for those who breach this section, which are of a criminal or administrative nature, as well as the obligation to repair any damage caused [1]. 


\subsubsection{Spanish Law 10/1998, of 21 April, on Waste}

Its purpose is to prevent the production of waste, establish the legal framework for its production and management, and promote its reduction, reuse, recycling and other forms of recovery, as well as regulating contaminated soils, in order to protect the environment and people's health. It is applicable by extension to, among other issues and the aspects that are expressly regulated in its specific provisions, the management of waste resulting from the prospection, extraction, recovery, disposal and storage of mineral resources, as well as from quarrying [2].

\subsubsection{Spanish Law 22/2011, of 28 July, on Waste and Contaminated Soils}

One of the purposes of this law is to regulate waste management by advancing measures that prevent its generation and mitigate the negative impacts on human health and the environment that are associated to their generation and management, improving resource use efficiency. Furthermore, its purpose is also to regulate the legal framework of contaminated soils. Waste hierarchy shall be applied by the relevant government bodies for the development of policies and legislation on the issue of waste prevention and management in order to attain the best global environmental result possible. The order of priorities is as follows: Prevention, reuse, recycling, other types of recovery (including energy recovery) and, lastly, disposal. Furthermore, it establishes waste policy resources, such as waste management plans and programmes, measures and economic instruments. It stipulates the obligations of the producer or any other initial owner as regards waste management, storing, mixing, packaging and labelling waste, as well as the obligations of the people responsible for managing the waste. In short, this law establishes the objectives and measures for waste management, specifically the collection, preparation for reuse, recycling, recovery and disposal of waste, the broadened responsibility of the producer and the sanctioning regime in relation to waste [3].

3.1.4. Order MAM/304/2002, of 8 February, which Publishes the Waste Recovery and Disposal Operations and the European List of Wastes

This Order acts under the protection of Spanish Law 10/1998, of 21 April, on waste. The first paragraph of section 2 of the third final provision of Spanish Law 10/1998, of 21 April, on waste, empowers the Ministry of the Environment to publish the European Waste Catalogue (EWC) (approved by Decision 94/3/EC of the Commission of 20 December) and the List of Hazardous Waste (LHW) (approved by Decision 99/404/EC of the Council of 22 December). Both Decisions have been replaced by Decision 2000/532/EC of the Commission of 3 May. Afterwards, Decision 2000/532/EC of the Commission of 3 May was replaced by Commission Decisions 2001/118/EC of 16 January, and by Council Decision 2001/573 of 23 July, which approves the European List of Wastes. The European List of Wastes merges the European Waste Catalogue and the List of Hazardous Waste into a single one. On the other hand, the second paragraph of section 2 of the third final provision of Spanish Law 10/1998, of 21 April, on waste, establishes that the Ministry of the Environment shall publish the list of waste recovery and disposal operations. This list was approved by Decision 96/350/EC, is applicable to all types of waste and allows for the appropriate application of the concepts of recovery and disposal. Two annexes are published at the end of this Order: Annex 1: Waste recovery and disposal operations (Part A: Disposal operations and Part B: Recovery operations) and Annex 2: European List of Wastes (ELW) [4].

\subsubsection{National Construction and Demolition Waste Plan (I PNRCD in Spanish) (2001-2006)}

The purpose of this Plan is to establish the ecological foundations and objectives for the appropriate environmental management of inert and similar CDW while in effect (2001-2006). Furthermore, it established a series of ecological objectives and suggests the instrumental, funding, monitoring and review measures of the Plan in order to carry them out. The Funding chapter includes both the estimate as well as the total budget for the infrastructures necessary for each Autonomous Community, such as recycling plants, dumping sites for inert materials and transfer plants, based on the 
amount of waste that each type of treatment will potentially receive. On the other hand, the same chapter also includes the funding methods for the various investments that are to be conducted, such as public and private initiatives in prevention and infrastructure, research, development and innovation $(\mathrm{R}+\mathrm{D}$ and innovation), as well as citizen awareness actions, statistical control and the training of specialised personnel. Lastly, the Monitoring and Review chapter of the Plan includes a series of tables showing in a quantitative way: The generation and recycling of CDW in different countries of the European Union, an estimate of the construction and demolition waste generation in each Autonomous Community, a forecast of construction and demolition waste management, assuming as a hypothesis a generation of $1000 \mathrm{~kg}$ per inhabitant per year; budgets regarding prevention, infrastructure investments, $R+D$ and innovation, raising awareness and training, statistical control and funding by the Ministry of the Environment [5].

\subsubsection{National Construction and Demolition Waste Plan (II PNRCD) (2008-2015)}

This Plan is included in Annex 6 of the National Integrated Waste Plan (PNIR 2008-2015 in Spanish), which emerges to improve the management of all waste generated in Spain, stimulate the different government bodies and agents involved in achieving ambitious ecological objectives, and comply with legal regulations, such as Spanish Law 10/1998 of waste and European Framework Directive 2006/12/EC (Table 1). This Plan (Table 1) establishes the objective of executing a suitable environmental management of hazardous waste included in the CDW list (an objective of mandatory compliance) as well as other objectives, such as the prevention at source of the generation of CDW, the application of the hierarchy principle, maximising recovery, improving the CDW treatment infrastructure network, closing dumping sites that cannot adapt to the legislation and adapting those that can.

Table 1. Objectives for Construction and Demolition Waste (CDW) for the years 2008, 2012, 2015. [6].

\begin{tabular}{lccc}
\hline \multicolumn{1}{c}{ Objective } & $\mathbf{2 0 0 8}$ & $\mathbf{2 0 1 2}$ & $\mathbf{2 0 1 5}$ \\
\hline Collection + appropriate & 80 & 95 & 100 \\
environmental management & & 10 & 20 \\
Prevention + reuse & & 25 & 40 \\
Recycling & 40 & 70 \\
Recovery of waste from & & & \\
construction materials & &
\end{tabular}

Furthermore, it establishes the intended measures for the development of this Plan, includes an estimate of the infrastructure necessary for the management of CDW and analyses the level of deficit in this field in the country. Likewise, it reveals the necessary budget for the application of the intended measures and infrastructure, and assesses the funding needed for the functioning of the Plan, its monitoring and review [6].

\subsubsection{Government Framework Plan for Waste Management (PEMAR in Spanish) (2016-2022)}

The essential purpose encompassed in this Plan is to replace the current obsolete linear economy with a circular economy, which reintegrates the materials of interest present in waste into the productive process again and again for the production of new products or raw materials, thus seeking that Spanish society progresses towards efficiency in terms of the use of resources.

One of the novelties this new version brings is that the Autonomous Communities must inexcusably meet the national goals for their territory. Waste generated in their territory must comply with the national objectives, except when sector regulation establishes specific criteria, and local entities must make all means available to meet these objectives. In essence, all autonomies are responsible for achieving compliance with the national objectives. Section 13 of this Plan is dedicated to the analysis of CDW, showing records of results of the goals established in the previous Plan, the qualitative and quantitative objectives, and guidelines that make it possible to accomplish said goals. 
The objectives established in the PEMAR, in short, are: To apply waste management hierarchy (reuse, recycling, recovery and disposal), to implement the selective collection of waste, boost measures to increase reuse and recycling as well as promoting this market, consider incineration as a recovery operation as long as energetic efficiency is achieved, discontinuing activities (in the case of not having the required authorisations), establishing a single procedure for the electronic registration of waste production and management, implement a deposit, refund and return system, and create a commission of coordination on waste with members from different government bodies [7]. Tables 2 and 3 show the quantitative objectives established by the PEMAR while in effect and number of transfer and treatment installations and dumping sites.

Table 2. CDW objectives for the years 2016, 2018, 2020 [7].

\begin{tabular}{cccc}
\hline Objective & $\mathbf{2 0 1 6}$ & $\mathbf{2 0 1 8}$ & $\mathbf{2 0 2 0}$ \\
\hline $\begin{array}{c}\text { Non-hazardous CDW (in \%) allocated to } \\
\text { being prepared for reuse, recycling and } \\
\text { other recovery operations (excluding } \\
\text { clean soils and stones) (minimum) }\end{array}$ & 60 & 65 & 70 \\
\hline $\begin{array}{c}\text { Disposal of non-hazardous CDW in } \\
\text { dumping sites (in \%) (maximum) }\end{array}$ & 40 & 35 & 30 \\
\hline $\begin{array}{l}\text { \% of clean soils and stones (EWL 17 05 } \\
\text { 04) used in ground and restoration, } \\
\text { refurbishing or filling works (minimum) }\end{array}$ & 75 & 85 & 90 \\
\hline $\begin{array}{c}\text { Disposal of clean soils and stones (EWL } \\
\text { 17 05 04) in dumping sites (in \%) of the } \\
\text { total volume of excavated natural } \\
\text { materials (maximum) }\end{array}$ & 25 & 15 & 10 \\
\hline
\end{tabular}

Table 3. Number of transfer and treatment installations and dumping sites that received CDW in 2013 [7].

\begin{tabular}{ccccc}
\hline $\begin{array}{c}\text { Autonomous } \\
\text { Community }\end{array}$ & Transfer Plants & $\begin{array}{c}\text { Permanent } \\
\text { Treatment Plants }\end{array}$ & $\begin{array}{c}\text { Mobile Treatment } \\
\text { Plants }\end{array}$ & Dumping Sites \\
\hline Andalusia & 92 & 119 & 21 & 71 \\
Aragon & 18 & 6 & 1 & 5 \\
Asturias & 3 & 4 & 5 & 1 \\
Balearic Islands & 6 & 2 & $\mathrm{n} / \mathrm{a}$ & 1 \\
Canary Islands & 0 & 23 & $\mathrm{n} / \mathrm{a}$ & 7 \\
Cantabria & 12 & 4 & 12 & 2 \\
Castilla-La Mancha & $\mathrm{n} / \mathrm{a}$ & 28 & 27 & 3 \\
Castile and Leon & 0 & 45 & 0 & 57 \\
Catalonia & 12 & 50 & 0 & $\mathrm{n} / \mathrm{a}$ \\
Ceuta & $\mathrm{n} / \mathrm{a}$ & $\mathrm{n} / \mathrm{a}$ & $\mathrm{n} / \mathrm{a}$ \\
Valencian Community & $\mathrm{n} / \mathrm{a}$ & $\mathrm{n} / \mathrm{a}$ & 0 \\
Extremadura & 16 & 21 & 1 & 5 \\
Galicia & 3 & 43 & 21 & 2 \\
La Rioja & $\mathrm{n} / \mathrm{a}$ & 16 & 0 & 4 \\
Community of Madrid & 10 & 14 & 0 & $\mathrm{n} / \mathrm{a}$ \\
Melilla & $\mathrm{n} / \mathrm{a}$ & $\mathrm{n} / \mathrm{a}$ & 19 \\
Region of Murcia & 2 & 4 & 32 & 7 \\
Navarre & $\mathrm{n} / \mathrm{a}$ & 7 & 3 & $\mathrm{n} / \mathrm{a}$ \\
Basque Country & $\mathrm{n} / \mathrm{a}$ & $\mathrm{n} / \mathrm{a}$ & 11 & 196 \\
\hline TOTAL & 174 & 386 & 134 & \\
\hline
\end{tabular}


3.1.8. Spanish Royal Decree 105/2008, of 1 February, which Regulates the Production and Management of Construction and Demolition Waste

Its purpose is to establish the legal framework for the production and management of construction and demolition waste, in order to encourage their prevention, reuse, recycling and other ways of recovery, ensuring that those allocated to disposal operations receive an appropriate treatment, and to contribute to a sustainable development of the construction activity. Furthermore, it also establishes the obligations that CDW producers and owners must comply with. The latter includes the minimum amounts of waste generation which, if surpassed, must be divided into fractions. Said fractions are detailed in this Royal Decree. Furthermore, it also establishes the system for the control of production, ownership and management of CDW, general obligations of the manager of these wastes, recovery activities, treatment with mobile plants in permanent waste recovery or disposal plants, disposal activities via depositing them in dumping sites, construction and demolition waste collection, transporting and storage, the use of inert waste in restoration, refurbishing or filling works, planning on CDW, administrative liability and sanctioning regime [8].

\subsubsection{Spanish Royal Decree 1247/2008, of 18 July, which Approves the Structural Concrete Standards (EHE-08)}

The purpose of this Royal Decree is the approval of the Structural Concrete Standards [9] (EHE-08) (EHE-08: Spanish legislation whose purpose is to regulate the design, execution and monitoring of concrete structures, both in construction and civil engineering works), which include a series of updates that entail the adaptation of this legislation to the prevailing European criteria regarding the demandable requirements for structures, as well as the addition of new construction techniques and materials, including those that have been recycled. Furthermore, these standards establish the requirements to take into account for the design and execution of concrete structures, both for construction as well as civil engineering, with the objective of achieving the security levels that are suitable for their purpose [10].

\subsection{Chilean Reality}

\subsubsection{Political Constitution of the Republic of Chile}

Point eight of Article 19 of Chapter III: On constitutional rights and duties, says that the Constitution ensures every person's right to live in a pollution-free environment. It is the State's duty to ensure that this right is not affected and to protect the preservation of nature. Laws may establish specific restrictions to the exercising of certain rights or freedoms to protect the environment [11].

\subsubsection{Chilean Law No. 19.300—Law on General Environmental Framework}

A law approved by the Ministry of the Presidency in 1994. It establishes the legislative framework that regulates the right to live in a pollution-free environment, the protection of the environment, the preservation of nature and the conservation of environmental heritage. It also regulates the instruments for environmental management such as the Strategic Environmental Assessment, the Environmental Impact Assessment System and the Access to Environmental Information, the Liability for Environmental Damage, the Inspection and Environmental Protection Fund, and Chilean environmental institutionalism [12].

3.2.3. NCh 3562: Waste Management-Construction and Demolition Waste and Excavation Material—Classification and Guidelines for a Management Plan

CDW are inert substances or objects, waste similar to that produced in the household and hazardous waste, which are generated during construction and/or demolition works and whose generator disposes of or has the intention or obligation of disposing of them in accordance with current legislation. The Management of CDW encompasses all the operative actions to which a construction 
and demolition waste is subjected to, including its gathering, stocking, transportation, pre-treatment, treatment and disposal.

This draft standard, prepared by the National Standards Institute [13] (INN in Spanish) (Non-profit private law foundation created by CORFO in 1973, as a technical body on the issue of infrastructure quality control (Chile)), is currently in a public consultation process. Some of its objectives are:

- Promote the integral management of inert waste and construction work excavation materials, to decrease their environmental, social and economic impact.

- Promote the reduction, reuse, recycling and recovery of waste.

- Ensure an appropriate waste classification and placement for the final disposal of the aforementioned waste.

It establishes basic considerations for the management of inert CDW from excavation, demolition or construction, which the various factors involved, must comply with, such as: Waste and excavation material generator (client and construction company), inert CDW manager (company or organisation that transports, recovers and disposes of it) and carrier of the excavation material for construction and demolition. Furthermore, it decrees the classification of waste from construction and/or demolition works and materials from excavation or roll forming. On the other hand, this standard does not establish basic considerations for the management of hazardous waste similar to that form households, which must be managed in accordance with current legislation.

This standard has 5 annexes, which are the following [14]:

- $\quad$ ANNEX A: List of inert CDW;

- ANNEX B: List of hazardous CDW;

- ANNEX C: List of CDW similar to that from households;

- ANNEX D: List of excavation material;

- ANNEX E: Minimum contents of a Management Plan.

3.2.4. Chilean Law No. 20.920-Framework for the Management of Waste, the Extended Liability of the Producer and the Promotion of Recycling

It was passed on 17 May 2016 and then published on 1 June of the same year. The body responsible for this law is the Ministry of the Environment. The purpose of this law is to decrease the generation of waste and promote its reuse, recycling and other types of recovery, through the implementation of the extended liability of the producer and other waste management instruments, with the goal of protecting the health of the people and the environment.

The execution of this law was inspired by a series of principles, such as gradualism, inclusion, waste management hierarchy, the principle of "he who pollutes, pays", free competition, the liability of the waste generator, transparency, traceability and disclosure.

For the purposes of the use and understanding of this law, it included a list of definitions. These are: Storage, life cycle, marketer, consumer, industrial consumer, distributor, ecodesign, disposal, generator, manager, management, reception and storage installation, handling, environmentally sound handling, best environmental practices, best techniques available, preparation for reuse, pre-treatment, priority product, producer of a priority product or producer, waste picker, recycling, collection, waste, reuse, management system, treatment, recovery and energetic recovery.

Chapter II of this law establishes everything related to waste management, such as prevention and recovery, obligations of waste generators, obligations of waste managers and obligations of waste importers and exporters.

On the other hand, Chapter III, named "of the extended liability of the producer", is comprised of three paragraphs. The first details the general provisions, establishing the concept of "extended liability of the producer", the obligations that priority product producers must comply with and the list of priority products. The second paragraph establishes the collecting and recovery goals and other associated obligations. Lastly, the third deals with everything related to waste management systems. 
Chapter IV of this law details the support mechanisms for the extended liability of the producer, and lastly, Chapters V and VI establish the information systems and inspection and sanction regimes [15].

\subsubsection{Integral Management of Solid Waste Policy (PGIRS in Spanish)}

This policy is born from the instructions provided by the Environmental Policy for Sustainable Development, approved by the Executive Council of the National Environment Commission (CONAMA in Spanish) in January 1998, which offered different tools to improve the deficiencies diagnosed in the current situation regarding waste handling, identifying the actions to develop, both in the short and medium terms.

The purpose of this policy is to guide the implementation of a hierarchical strategy, promoting the prevention of its generation and, if its prevention is not possible, to promote, in this order, its reuse, recycling, energetic recovery, treatment and final disposal, all for the purposes of protecting the health of the people and the environment.

Furthermore, one of the important points included in this policy is the suggestion of the need to have an integral management of waste, whose starting point is the very development of the product. This concept is already successfully implemented in a majority of developed countries and the main objective is to prevent its generation. In the case where this is not possible, minimisation measures are followed in a hierarchical and orderly manner. These are: Reduction, reuse and recycling; with treatment and final disposal as the last and least desirable option.

On the other hand, this management policy includes the different guiding foundations and principles that surround its development, as well as its different lines of action, which are the specific measures that allow compliance with and the success of the objectives proposed by this policy; and the regulatory framework, which establishes the goals to be reached in the short and medium term [16].

\subsubsection{Clean Production Agreement (APL in Spanish)}

This is a voluntary agreement held between the representative corporate association of a productive sector and public bodies which are competent on several issues, the purpose of which is to improve the productive and environmental conditions in terms of hygiene and labour safety, energetic and hydrological efficiency, emission decrease, waste recovery, good practices, productive encouragement and other issues addressed by the agreement, looking to create synergies and economies of scale, as well as compliance with the environmental laws, which favour an increase in productivity and competitivity among companies.

To strengthen this tool, a key factor is the development of four Official Chilean Standards, which establish the guidelines for the development and implementation of, and accreditation of compliance with, Clean Production Agreements:

- NCh 2797.Of2003 “Clean Production Agreements (APL)—Specifications".

- NCh 2807.Of2003 "Clean Production Agreements (APL)—Diagnosis, Monitoring and Control, Final assessment and Accreditation of compliance".

- NCh 2825, on "Requirements for the final assessment auditors".

- NCh 2796, on "Vocabulary" applied to this Accreditation System.

Since the year 2016, the National council for Clean Production has decided to publicly report the decreases of emissions achieved through Clean Production Agreements in accordance with the Directive of the Ministry of the Environment. Between the years 2012 and 2016, estimated reductions reached 3,242,301 tonnes of $\mathrm{CO}_{2}$, making the APL the first Chilean mitigation action to report reductions back to the United Nations [17]. 


\subsubsection{Research Programmes Conducted in Chile}

First Report on the Handling of Solid Waste in Chile (Based on the "Gathering, Analysis, Generation and Publication of National Information on Solid Waste in Chile" Project, Year 2010)

This report has been developed by CONAMA and summarises the main results of the "Gathering, analysis, generation and publication of national information on solid waste in Chile" project, completed in the year 2010.

In May of that year, Chile became the first full member of the Organisation for Economic Cooperation and Development (OECD) in South America. This status enforces a high standard on their public policies on environmental issues. With this, one of the commitments of Chile is to develop time series mainly associated to the generation, recovery and disposal of waste that facilitates the obtaining of indicators. The information exhibited in this report is part of the objectives of the Integral solid waste management policy. Furthermore, it meets the commitments that Chile has with the OECD regarding disseminating information on the handling of waste to the population. Among other sources, surveys, waste generation factors and diagnostic studies were referred to in order to conduct this report. The Government and the Ministry of the Environment have set as the main goal to continue improving on waste treatment issues. The ideal scenario is to enforce measures to stop seeing waste as rubbish, but instead as a raw material which can be minimised, reused and recycled.

This report is part of the "Gathering, analysis, generation and publication of information on solid waste in Chile" project, conducted in 2009. Its purpose is to deliver a general viewpoint of the amounts and handling of waste in Chile. The idea is to continue examining this information in coming years, in order to improve the national management standards.

As of the year 2005, through agreement No. 265 of the Council of Ministers of CONAMA, the country has:

- Integral Solid Waste Management Policy (PGIRS).

- Action Plan, which lasts until 2010.

The purpose of the Integral Solid Waste Management Policy is to guide the implementation of a hierarchical strategy, promoting the prevention of its generation and, if its prevention is not possible, to promote, in this order, its reuse, recycling, energetic recovery, treatment and final disposal, all for the purposes of protecting the health of the people and the environment. Likewise, among the lines of action until 2010, is to "Merge and complete the regulatory framework". In regard to this there is the Waste Act (Chilean Law No. 20,92), which includes essential concepts such as: Hierarchical strategy, extended liability of the provider and integral management of waste.

Chile, by becoming a member of the OECD, must comply in the established terms, with an information structure associated to solid waste which takes into account a series of requirements regarding definitions, regulations and the cross-border movement of waste, among others. As of 2010, Chile has a new environmental government body comprised of:

- Ministry of the Environment.

- Superintendency of Oversight.

- Environmental Assessment Service.

- Environmental Tribunal.

With the purpose of standardising the requirements, analysis and comparing of information on solid waste on an international level, the OECD suggested a detailed classifying of waste generation sources, which is linked to the classifications used in studies related to solid waste in Chile. Taking into account the main information structure available in the country and the separation of the source of the solid waste, they are classified as industrial solid waste and municipal solid waste [18]. 
Final "Gathering, Analysis and Generation of Information on Construction Waste" (Solid Waste Group of the Pontificia Catholic University of Valparaíso PUCV) Report

Its purpose is to provide complete information on the generation and handling of construction waste in Chile, in order to meet the requirements enforced by the OECD.

Furthermore, the following points can be established as specific objectives:

- Review the available information on construction and demolition waste.

- Complete and update the information on the generation and handling of construction waste, specifying the amounts and associated characteristics.

- Fill out the information requested on the OECD tables.

- The executing of the following activities was requested in order to conduct this report:

- To review the available information associated to construction waste on a national and international level.

- To modify and update the information associated to construction waste in Chile.

- To complete with the background information obtained from the model, the waste policy information on the OECD tables.

- To study of the "Gathering, analysis, generation and publication of national information on solid waste in Chile" report.

On the other hand, different measures are suggested to be added to the PGIRS. These are born from the results and conclusions obtained during the development of this study and are suggested with the purpose of continuing to improve the development of future research. The first one is a summary table which includes several items, then their current development situation and, lastly, the desired situation or condition to be met. Lastly, different ideas are suggested to enable the obtaining of future information [19].

- Analysis of waste streams.

- Waste generation estimate.

- Assessment of the most favourable scenario for future management.

Third Report on the State of the Environment, 2017 Edition. Chapter 13: Waste

This report corresponds to the third instalment, corresponding to the year 2017, which delivers an update of the country's environmental indicators and statistics, which makes it possible to monitor the evolution of the main components of the environment, as well as some of the problems that affect the country on this issue.

This report corresponds to the continuation of the first and second report on the environment, from the years 2013 and 2015, respectively. Likewise, as recommended by the OECD and as part of the advanced work on the issue of Sustainable Development Goals, as of this report, indicators are added which make it possible to measure the progress registered by the country regarding green growth, one of the great challenges in the medium and long term in order to promote an economic development which ensures the maintenance of the resources and the services they provide for people's quality of life [20].

Construction Waste in Antofagasta, Preliminary Study (by the Studies Unit of the Chilean Construction Chamber (CCHC in Spanish), in Antofagasta)

This study was conducted by the Studies Unit of the Chilean Construction Chamber (CCHC) in Antofagasta together with the work team from the Civil Construction degree of the Catholic University of the North, with the purpose of delivering a tool that helps improve the management of construction and demolition waste in this region.

A diagnosis of the current situation of construction waste management is submitted in this document. This assessment shows monthly generation indexes of these wastes, the role that construction companies must fulfil in the management of construction waste, and analyses potential options of locations to be used as final disposal points. Furthermore, an analysis of construction wastes, their origin, 
composition and classification are also submitted, as well as their optimal management and the review of an example of waste management both in Chile and abroad.

\subsection{Interviews with Experts}

Table 4 shows the interviewed experts from the construction sector of Chile.

Table 4. Experts interviewed in Chile.

\begin{tabular}{lcl}
\hline Professional & TVIAL Ltda. Construction \\
Roberto Tedias A. & Company \\
Jorge Fuentes F. & BROTEC Construction Company \\
Francisco Mora F. & Metropolitan Housing and Town \\
Planning Service (SERVIU) & National Roads Laboratory \\
Gabriela Muñoz R. & National Roads Laboratory \\
Gabriel Palma P. & Ministry of Public Works \\
Víctor Reyes G. & \\
&
\end{tabular}

3.3.1. Roberto Tedias Araya (Construction Engineer, General Manager of the TVIAL Ltda.

Construction Company), Jorge Fuentes Fuentes (Civil Engineer, Technical Manager of the Brotec Ltda. Construction Company)

They are both aware of the future shortage of aggregates in Santiago de Chile, which is why they see recycling as a solution. They argue that it could be used directly on site without a washing process, which is conducted in a laboratory in order to run tests. Their experience in the use of recycled aggregates has been with crushed granular base and subbase, with structural landfill or embankment.

\subsubsection{Francisco Mora Frtiz (Civil Engineer, Metropolitan SERVIU)}

He says that recycled aggregate is not considered a construction material in any Chilean regulations, and that adding it would be quite interesting considering the future shortage of natural aggregate in the metropolitan region. Metropolitan SERVIU is interested in including sustainability in its regulations, but the problem is that there is no document which allows its insertion in the institution. Documents that state both technical and environmental specifications on the use of recycled materials are required. His argument is based on the fact that, for now, it is not good business because it cannot compete with natural aggregate. His experience with recycled aggregates is the following: Filler for sewers and crushed granular base and subbase as an aggregate to manufacture concrete for footpaths. At the SERVIU they are aware of the NCh 3562 standard. 


\subsubsection{Gabriela Muñoz Rojas, Gabriel Palma Papic (National Roads Laboratory)}

The National Roads Laboratory has applied the Rubblizing (Technique that consists of fracturing concrete pavement through resonance, in order to intertwine the wastes, turning them into crushed granular base or subbase), making it possible to obtain recycled aggregate to be used as crushed granular base and subbase in the same location. They have used recycled aggregates in embankments and other types of fillers.

\subsubsection{Víctor Reyes González (Civil Engineer, Ministry of Public Works)}

The Ministry of Public Works is aware that natural aggregate is gradually becoming a less and less available resource, and that there will be greater difficulties to extract it from deposits or quarries. The closest that has been done regarding the use of recycled materials, is the RAP (RAP: Recycled Asphalt Pavement (Asfalto Reciclado para Pavimento)). At the Ministry of Public Works there is an interest to include innovation in regulations, and for this purpose there is a defined protocol which makes it possible to submit technology proposals to a specialised unit, which awards the use of "test sections" through the National Roads Laboratory. The greater the use of recycled materials, the less exploitation of natural aggregates, which will lead to a decrease in the levels of $\mathrm{CO}_{2}$ released into the environment.

\subsection{Technical Analysis}

The materials considered in this study are concrete (for manufacturing roads), as well as crushed granular base and subbase (used as the support base in said roads as well as those built with asphalt). With a rising tide of adoption of recycled aggregate (RA) for construction, investigation on ways to improve the quality of RA has been overwhelming. The adoption of RA brings benefits including savings in the limited landfill spaces and the use of natural resources. However, the poorer quality of RA often limits its utilization to low grade applications such as sub-grade activities, filling materials and low grade concrete. The major reason that affects the quality of RA is the large amount of cement mortar remains on the surface of the aggregate, resulting in higher porosity, water absorption rates and thus a weaker interfacial zone between new cement mortar and aggregates, which weakens the strength and mechanical performance of concrete [21]. The results of a recent study [22] indicated that RA affect the resulting mechanical strength of hardened concrete due to the lower specific gravity and higher water absorption as compared to the natural aggregates (NA). Recycled coarse aggregate (RCA) has about $28 \%$ higher bonded mortar content (BMC) with porosity of bonded mortar (BM) almost double as that of recycled fine aggregate (RFA). This leads to inferior interface between aggregate and cement paste thereby affecting the overall concrete properties. The presence of mortar has been reported as the main factor causing the lower quality of recycled concrete aggregates (RCA) when compared to natural aggregates (NA). A novel microwave-assisted technique to increase the quality of RCA by partially removing the mortar adhering to RCA particles and breaking up the lumps of mortar present in RCA has been studied [23]. The intrinsic properties of recycled coarse aggregates (RC), associated with bonded mortar, can be modified with two different pre-treatment techniques viz-a-viz $\mathrm{HCl}$ pre-treatment and $\mathrm{Na}_{2} \mathrm{SO}_{4}$ pre-treatment [24]. Other authors report an experimental study to improve the properties of recycled concrete aggregates (RCA) by their impregnation with polyvinyl alcohol [25].

Concrete: The Roads Manual (Document produced for the purpose of establishing policies and unifying procedures and instructions in the various technical areas to which they apply (Chile)) establishes a minimum resistance of 5.0 MPa to the bending tension test. According to this requirement, it would be hard to reach this resistance using $100 \%$ recycled aggregate, as its use requires a larger amount of water, and therefore has lower mechanical resistance. It is only possible to do this when using recycled aggregates that have been obtained by demolishing high-performance concretes. It cannot be used in these amounts, as a greater amount of cement has to be used, which would not make it feasible in economic terms. Additionally due to the high likelihood of being affected by shrinking, this would cause cracks. The recommended amount of demolition waste to use according to Spanish literature 
is up to $20 \%$ of the weight. One of the features to consider is the curing based on a superficial film (membrane curing), as well as the superficial saturation [26].

To make it so that concrete with recycled aggregates reaches an ideal resistance, the surface of the stone material must have a minimum amount of adhered mortar. To do so, there are two possible methods to clean the said surface. The first is to wash it, which has the inconvenience of requiring a large amount of water, a resource that is currently scarce in the country and which would therefore noticeably increase costs. The other solution would be to implement a blower system, which makes it possible to clean the surface, but the problem is that doing so increases the levels of pollution, which is an equally critical factor in Santiago and the other regions [27-32].

Crushed granular base: The Roads Manual establishes the need to obtain a CBR bearing ratio of $60 \%$. The values achieved in this field in international literature are of the order of $40 \%$ for subbases, conducted with asphalt waste, and of around $60 \%$ when conducted with concrete demolition waste. The use of crumb rubber in certain proportions is also considered, in order to not compromise its structural stability. The structural properties increase even more if asphalt waste such as RAP is used [33-36].

\subsection{Result Analysis}

Taking into account that which has been analysed, the following can be concluded.

\subsubsection{Technical Legislation}

In Spain there is technical legislation such as documents PG-3 and EHE-08, which consider the use of recycled aggregates, establishing limits, dosage and other aspects. In Chile however, current legislation only considers recycled materials in asphalt mixtures. The Roads Manual has specifications on the use of RAP, for example. However regarding the use of recycled aggregates, there is no legislation that allows its use in road works as of yet.

The interviewees mention that, in general, the construction sector is resisting considering the use of recycled aggregates, as there is distrust about its properties and a lack of knowledge on its benefits when used in road works.

\subsubsection{Legal Legislation}

In Spain there are laws that mandate the use of recycled materials and as well as penalising an inappropriate processing of CDW. The likely significant effects of projects on the environment must be considered in relation to criteria set out in points 1 and 2 of the Annex, with regard to the impact of the project on the factors specified in Article 3(1), taking into account, among other aspects, the possibility of effectively reducing the impact. [37]. The different environmental assessment systems operating within Member States should contain a set of common procedural requirements necessary to contribute to a high level of protection of the environment. [38]. The Public Administrations will adjust their actions regarding environmental assessment to the principles of institutional loyalty, coordination, mutual information, cooperation, collaboration and coherence [39].

In Chile, despite the existence of laws that regulate and penalise the disposal of waste, they only reference other types of waste (domestic and organic, among others), leaving construction and demolition waste out of their reach. As per the comments made by the interviewed professionals, they say that, as there are no laws that make recycling mandatory, it is hard to create a sustainable culture in the construction sector. Furthermore, within the administrative bases there is also no requirement to use recycled materials, not even a certain percentage.

In Spain,

there is:

- $\quad$ Spanish Law 10/1998;

- $\quad$ Spanish Law 21/2013;

- Spanish Law 22/2011; 
- Order MAM/304/2002;

- Spanish Royal Decree 105/2008;

- $\quad$ Spanish Royal Decree 1247/2008;

- I PNRCD (2001-2006);

- II PNRCD (2008-2015);

- PEMAR (2016-2020).

\section{In Chile,}

there is:

- Chilean Law No. 19.300;

- Chilean Law No. 20.920;

- NCh 3562: Waste Management;

- Integral Solid Waste Management Policy (PGIRS)

- Clean Production Agreement (APL);

- Research programmes carried out in Chile.

\subsubsection{RESCON Management Plan}

In Spain, the CDW management plans are set, and have been dealt with since the year 2008 through Spanish Royal Decree 105/2008, whereas in Chile the only requirement is a certificate that states that the dumping site is one that has been authorised. There is no law that mandates the establishment of a plan to manage waste generated in works. Standard NCh 3562 tries to solve this situation.

\subsubsection{Ministerial Structure}

\section{In Spain,}

- There is an entity known as the Ministry of Public Works and Transport, which branches out into several Departments and Administrations. The General Administration of Architecture, Housing and Land, and the General Administration of Roads, are those responsible for Urban Roads and Interurban Roads, respectively (Figure 2).
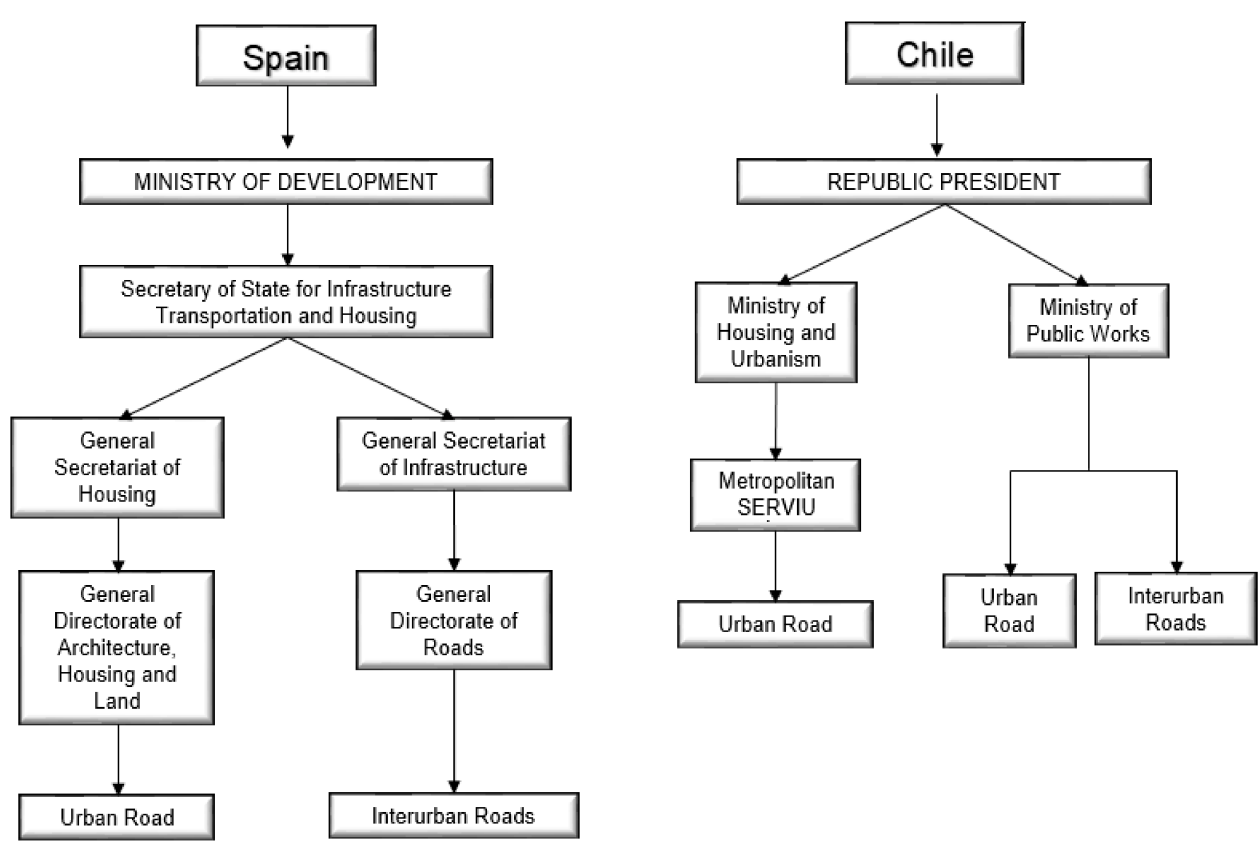

Figure 2. Government reality comparison between Spain and Chile. 


\section{In Chile,}

- There is no responsible entity such as the mentioned Spanish one (Figure 2). There are only Ministries of Housing and Urban Development (which, through the SERVIU, is responsible for Urban Roads) and the Ministry of Public Works (responsible for Interurban Roads).

\subsubsection{Infrastructure}

In Spain, the CDW plans (PNRCD I, PNRCD II, PEMAR) establish the objectives for CDW in each respective application period, as mentioned in Tables 1 and 2. Furthermore, the PEMAR (2016-2022), establishes the number of permanent and mobile plants and dumping sites, as can be seen on Table 5 .

Table 5. Number of plants and dumping sites in Spain.

\begin{tabular}{cc}
\hline \multicolumn{2}{c}{ PEMAR (2016-2022) } \\
\hline Transfer Plants & 174 \\
Permanent Treatment Plants & 396 \\
Mobile Treatment Plants & 134 \\
Dumping sites & 196 \\
\hline
\end{tabular}

On the other hand, in Chile there are only two companies related to CDW. One of them is RESICO, where recycled aggregates are produced from concrete waste and which are then commercialised in two sizes ( $3^{\prime \prime}$ and $\left.1 \frac{1}{2} "\right)$, and the other is REGEMAC, a company which transfers this construction waste to authorised dumping sites.

In Spain there are different treatment plants and dumping sites.

In Chile there are only a few companies dedicated to recycling concrete aggregates (Table 6).

Table 6. Plants authorised for the disposal of CDW and debris.

\begin{tabular}{ccc}
\hline No. & Company & Commune \\
\hline 1 & REGEMAC & Puente Alto \\
2 & SOCIEDAD BALTIERRA S.A. & Puente Alto \\
3 & SEMOT LTDA. & Puente Alto \\
4 & POZO AEROPUERTO AMB & Pudahuel \\
5 & NEXO RESIDUOS LTDA. & Pudahuel \\
6 & IDEA CORP S.A. & San Bernardo \\
7 & MARGA MARGA S.A. & San Bernardo \\
8 & SOC. PÉTREOS S.A. & Padre Hurtado \\
9 & CERROS DE RENCA & Quilicura \\
10 & RINCONADA S.A. & Maipú \\
11 & SOC. AGRÍCOLA PIZARRO LTDA. & Pirque \\
\hline
\end{tabular}

\subsubsection{Implementation of Recycled Aggregates}

In Spain, the use of recycled aggregates has become standard practice, to the extent that this type of material is in the market, and with seals of quality. This situation makes it possible to define a wide variety of implementations, such as granular base and subbase, the manufacturing of test pieces (with a quality of up to G-40) (In accordance with Chilean standard NCh 170, Of. 2016 "Concrete-General Requirements". Mechanical resistance to compression is measured in Degrees, in cylindrical test pieces with a $15 \mathrm{~cm}$ diameter and $30 \mathrm{~cm}$ height.), concrete prefabs, fillers and embankments, among others.

Meanwhile, in Chile, the interviewed professionals mention a series of implementations such as granular base and subbase. The benefit of this context is that demolition waste can be used immediately, as it can be crushed in situ and then installed right away in the area where the future road project will be executed, aside from the fact that studies back this way of using this type of waste. When dealing 
with concrete pavement waste, bearing ratios close to $80 \%$ can be obtained, whereas asphalt pavement waste can reach a CBR value of $40 \%$ at most, which is why its use is limited to granular subbase.

On the other hand, the use of recycled aggregates is not recommended for manufacturing concretes, due to the low resistance levels obtained in tests conducted in their installations, coinciding with the observations made by the construction companies. In practice, the interviewees mention that, despite there being several methods for applying recycled aggregates in works, and the will to apply sustainability in the sector, there are factors that hinder its execution, as in Chile there is still no specific sustainable culture, a process which is currently being developed.

\subsubsection{Solutions Proposed by the Experts}

The experts offer solutions in accordance with the Chilean reality. All interviews were conducted in October 2018 (Tables 7-11):

Table 7. Opinion by Roberto Tedias Araya-Jorge Fuentes Fuentes.

\begin{tabular}{ll}
\hline \multicolumn{1}{c}{ Existing Problem } & \multicolumn{1}{c}{ Proposed Solution } \\
\hline $\begin{array}{l}\text { There are no laws that mandate the creation of a } \\
\text { management plan for waste generated during } \\
\text { construction. }\end{array}$ & $\begin{array}{l}\text { The creation of NCh } 3562 \text { solves this item. The } \\
\text { environmental authorities are the ones responsible for } \\
\text { implementing these obligations in the sector. }\end{array}$ \\
\hline $\begin{array}{l}\text { There is a lack of knowledge on standard NCh } \\
\text { 3562-Waste management. }\end{array}$ & $\begin{array}{l}\text { When the standard is approved, its use must be } \\
\text { facilitated through training on its appropriate } \\
\text { implementation }\end{array}$ \\
\hline $\begin{array}{l}\text { Technical legislation does not include recycled } \\
\text { aggregate as a construction material. }\end{array}$ & $\begin{array}{l}\text { Including it in all of the country's technical legislation } \\
\text { (Roads Manual, NCh, SERVIU regulations, among } \\
\text { others). To this point, only the Roads Manual } \\
\text { includes recycled materials (RAP). }\end{array}$ \\
\hline
\end{tabular}

Table 8. Opinion by Roberto Francisco Mora Fritz.

\begin{tabular}{ll}
\hline \multicolumn{1}{c}{ Existing Problem } & \multicolumn{1}{c}{ Proposed Solution } \\
\hline $\begin{array}{l}\text { There is no procedure that allows the insertion of } \\
\text { research or innovation documents. }\end{array}$ & $\begin{array}{l}\text { Create a protocol that streamlines the insertion of } \\
\text { research on the use of recycled aggregates in } \\
\text { construction. } \\
\text { Establish incentives and/or rewards for the most } \\
\text { innovative ideas. }\end{array}$ \\
\hline $\begin{array}{l}\text { There is no great interest in using recycled aggregates } \\
\text { in paving works, due to the lack of technical } \\
\text { knowledge on behalf of public bodies. }\end{array}$ & $\begin{array}{l}\text { Promote recycled aggregates through research } \\
\text { conducted in the sector, showing the benefits } \\
\text { compared to its natural counterpart in different } \\
\text { implementations in road and interurban works. }\end{array}$ \\
\hline
\end{tabular}

Table 9. Opinion by Gabriela Muñoz Rojas-Gabriel Palma Papic.

\begin{tabular}{ll}
\hline \multicolumn{1}{c}{ Existing Problem } & \multicolumn{1}{c}{ Proposed Solution } \\
\hline $\begin{array}{l}\text { In tests conducted on concretes with recycled } \\
\text { aggregates, the results were critical due to the low } \\
\text { resistance of the test pieces, both to compression and } \\
\text { bending tension. }\end{array}$ & $\begin{array}{l}\text { The use of concretes manufactured with recycled } \\
\text { aggregates is recommended in cases where the } \\
\text { resistance is not a critical factor. }\end{array}$ \\
\hline
\end{tabular}

Table 10. Opinion by Gabriela Muñoz Rojas—Gabriel Palma Papic.

\begin{tabular}{ll}
\multicolumn{1}{c}{ Existing Problem } & \multicolumn{1}{c}{ Proposed Solution } \\
\hline $\begin{array}{l}\text { In the country there are no incentives to make use of } \\
\text { recycled aggregates, due to their cost being greater } \\
\text { than their natural counterpart. }\end{array}$ & $\begin{array}{l}\text { Establish in the administrative bases of the projects to } \\
\text { be tendered, a certain percentage of reuse of } \\
\text { demolished materials based on technical criteria. }\end{array}$ \\
\hline
\end{tabular}


Table 11. In accordance with the experts': Factors must be considered in order to analyse the use of recycled aggregates.

\begin{tabular}{|c|c|c|}
\hline Situation & Benefits & Disadvantages \\
\hline $\begin{array}{l}\text { Washing and blowing of CDW } \\
\text { from concrete pavement } \\
\text { demolitions. }\end{array}$ & $\begin{array}{l}\text { Removes the layer of mortar adhered to the } \\
\text { Surface of the CDW. }\end{array}$ & $\begin{array}{l}\text { High cost per } \mathrm{m}^{3} \text { of water and high levels } \\
\text { of pollution. }\end{array}$ \\
\hline $\begin{array}{l}\text { Installation of a mobile } \\
\text { crushing plant on site. }\end{array}$ & $\begin{array}{l}\text { Makes it possible to crush demolition waste } \\
\text { in situ. } \\
\text { Decrease of the transport cost of natural } \\
\text { aggregate to the site. } \\
\text { Decrease of the transport cost of } \\
\text { construction waste to the dumping } \\
\text { site.Decrease in pollution levels from lorries. }\end{array}$ & $\begin{array}{l}\text { There is no appropriate space to install } \\
\text { this machinery. } \\
\text { Possible expansion of the project's } \\
\text { deadline. } \\
\text { Additional cost for the extra on-site use } \\
\text { (in the case of communes that apply a tax } \\
\text { for the use of a public asset. } \\
\text { High machinery rental and purchase cost. }\end{array}$ \\
\hline Rubblizing & $\begin{array}{l}\text { Makes it possible to demolish the existing } \\
\text { pavement and generate a layer of granular } \\
\text { base in situ. } \\
\text { Decrease of the transport cost of natural } \\
\text { aggregates to the site. } \\
\text { Decrease of the transport cost of the } \\
\text { construction waste to the dumping site. } \\
\text { Decrease in pollution levels from lorries. }\end{array}$ & High machinery rental and purchase cost. \\
\hline
\end{tabular}

\section{In Spain,}

the following products are manufactured for construction:

- Concrete test pieces (with a quality of up to G-40);

- Granular bases;

- Granular subbases;

- Securing and covering of pipes;

- Draining layers;

- Prefabricated pieces of concrete;

- Embankments;

- Fillings;

- Cement floor and cement gravel.

\section{In Chile,}

- Manufacturing of concrete test pieces (with a quality of up to G-30);

- Granular base;

- Granular subbase.

\subsection{Research Works}

\section{In Spain,}

- Companies are willing to support research works as a result of the change in mentality of European countries.

- European Union initiatives regarding applying a more sustainable outlook to the different economic sectors (e.g., construction), due to the possible shortage of aggregates endured in the continent.

\section{In Chile,}

- There is little willingness by companies to invest knowledge and collaborate with research projects. 


\subsection{Continental Reality}

\section{In Spain,}

- Belongs to the European Union.

In Chile,

- $\quad$ Belongs to the Pacific Alliance, MERCOSUR and the Organisation of American States (OAS).

\subsection{Insertion into the Market}

\section{In Spain,}

- Recycled products from CDW are flagged with the "CE"mark. In French this means Conformité Européenne or European Conformity. It corresponds to a European mark for certain products or industrial groups.

- In Catalonia in 2016, $48 \%$ of CDW was recovered.

- It is predicted that by 2020, the recycled aggregates market will have developed enough so that its entire production is absorbed in different uses.

\section{In Chile,}

- Crushed granular base measuring $<3$ ” and $<1 \frac{1}{2}$ “ is manufactured.

\section{Conclusions}

After analysing the Chilean and Spanish realities regarding waste management, the following is concluded:

1. The addition of recycled aggregate in Chilean technical legislation is suggested, both in the Roads Manual of the Ministry of Public Works as well as in the CNETOP of the SERVIU.

2. The creation of laws that penalise the deficient management of construction works, prohibit the extraction of natural aggregates in a gradual way and force companies to recycle or incentivise them to invest in technologies that enable the development of construction sustainability is suggested.

3. Even though recycled aggregates have been used in the construction of road works, its use is low due to:

- Lack of knowledge of the properties of recycled aggregates and its potential performance in construction works.

- High quality of natural aggregates and their extensive availability on the market.

- High manufacturing cost.

- Conservative attitude in the establishment of technologies and low tolerance of their performance by government bodies and construction companies.

- Investing in projects that encourage the use of recycled aggregates is recommended.

4. In road works and urban roads there is no construction and demolition waste management plan. Proof of this is the inexistence of a hierarchical process for its treatment, as is done in Spain. The only document required by current Chilean legislation is a certificate that proves that the dumping site is authorised. The approval of the NCh 3562 standard project would make it possible to solve both problems.

5. Both the Ministry of Public Works and the SERVIU have the intention of including recycled aggregates in their respective legislations. The difference between them is that the former has a protocol that allows the entrance of innovative proposals (with a prior analysis by the National Roads Laboratory it can make the Roads Manual). The said protocol does not exist in the latter, despite having proved 
that recycled aggregates can be used when complying with the required specifications. Establishing a project admission system at the SERVIU (similar to the Ministry of Public Works) is recommended.

6. In Chile there is no ministry that fulfils the same function as the Spanish Ministry of Public Works and Transport. A similar entity is required in order to focus exclusive attention on these types of works and promote the use of recycled materials in them. However, as proposing this approach is not very feasible, boosting the functions of the Ministry of the Environment is recommended, in such a way that recycling and sustainable practices are an equal part of all the economic sectors of the country.

7. In the bidding for tenders phase, establishing measures that make it possible to estimate the amount of waste that will be allocated to recycling is suggested.

8. In Chile there is no infrastructure (treatment, transfer and final disposal plants) that enable the receival and treatment of CDW generated in works. Building them is proposed, thus generating optimal (construction) waste management processes, as is done in Spain.

Author Contributions: Conceptualisation and methodology, M.D.; Writing-original draft preparation, M.D., M.B.A., M.M.J. and D.B.; Writing—review and editing, M.D. and D.B.; Supervising, D.B.

Funding: This research received no external funding.

Acknowledgments: Adrián Díaz González, Civil Engineer of Civil Works, and the Santiago de Chile University, for their support in conducting this study.

Conflicts of Interest: The authors declare that they have no conflicts of interest.

\section{References}

1. Constitución Española; Agencia Estatal Boletín Oficial del Estado: Madrid, Spain, 1978.

2. Ley 10/1998, de 21 de abril, de Residuos; Órgano Jefatura del Estado: Madrid, Spain, 1998.

3. Ley 22/2011, de 28 de Julio, de Residuos y Suelos Contaminados; Órgano Jefatura del Estado: Madrid, Spain, 2011.

4. Orden MAM/304/2002, de 8 de Febrero, por la que se Publican las Operaciones de Valorización y Eliminación de Residuos y la Lista Europea de Residuos; Agencia Estatal Boletín Oficial del Estado: Madrid, Spain, 2002.

5. Plan Nacional de Residuos de Construcción y Demolición (I PNRCD) 2001-2006; Agencia Estatal Boletín Oficial del Estado: Madrid, Spain, 2006.

6. Plan Nacional Integrado de Residuos (PNIR) 2008-2015; Anexo 6; Agencia Estatal Boletín Oficial del Estado: Madrid, Spain, 2008.

7. De Galarreta, M.C. Comentario al Plan Estatal Marco de Gestión de Residuos (PEMAR) 2016-2022; Spain, 2016. Available online: http://www.perseaconsultores.es/plan-estatal-marco-de-gestion-de-residuos-pemar2016-2022/ (accessed on 2 April 2018).

8. Plan Estatal Marco de Gestión de Residuos (PEMAR) 2016-2022; Spain, 2016. Available online: https://www. aprr.eus/wp-content/uploads/2016/11/20151106PEMAR-2016_2022_apartado-13_pag96.pdf (accessed on 2 April 2018).

9. EHE-08 Instrucción de Hormigón Estructural. Available online: https://www.activatie.org/web/publicacion. php?id=380 (accessed on 22 February 2018).

10. Real Decreto $1247 / 2008$, de 18 de julio, por el que se Aprueba la Instrucción de Hormigón Estructural (EHE-08); España, 2008. Available online: https://www.boe.es/eli/es/rd/2008/07/18/1247 (accessed on 3 April 2018).

11. Dirección de Vialidad. Manual de Carreteras. Available online: http://www.vialidad.cl/areasdevialidad/ manualdecarreteras/Paginas/default.aspx (accessed on 12 April 2018).

12. Ley 19.300. Ley Sobre Bases Generales del Medio Ambiente; Chile, 1994. Available online: http://www.conaf. cl/wp-content/files_mf/1370463346Ley19300.pdf (accessed on 3 April 2018).

13. Constitución Política de la República de Chile; Chile, 1980. Available online: https://www.camara.cl/camara/ media/docs/constitucion_politica.pdf (accessed on 23 April 2018).

14. NCh 3562: Gestión de Residuos-Residuos de construcción y demolición (RESCON) y Material de Excavación-Clasificación y Directrices Para Plan de Gestión; Chile. Available online: http://www.inn. cl/desarrollo-programa-normas-chilenas (accessed on 13 April 2018). 
15. Ley 20.920. Ley Marco para la Gestión de Residuos, la Responsabilidad Extendida del Productor y Fomento al Reciclaje; Chile, 2016. Available online: https://mma.gob.cl/wp-content/uploads/2015/06/PresentacionLEY-REP-20920_Junio_2016.pdf (accessed on 6 February 2018).

16. Etxeberria, M.; Vázquez, E.; Marí, A.; Barra, M. Influence of amount of recycled coarse aggregates and production process on properties of recycled aggregate concrete. Cem. Concr. Res. 2007, 37, 735-742. [CrossRef]

17. Li, J.; Saberian, M.; Thach, B.; Nguyen, B. Effect of crumb rubber on the mechanical properties of crushed recycled pavement materials. J. Environ. Manag. 2018, 218, 291-299. [CrossRef] [PubMed]

18. Domingo-Cabo, A.; Lázaro, C.; López-Gayarre, F.; Serrano-López, M.; Serna, P.; Castaño-Tabares, J. Creep and shrinkage of recycled aggregate concrete. Constr. Build. Mater. 2009, 23, 2545-2553. [CrossRef]

19. Dilbas, H.; Simsek, M.; Çakır, Ö. An investigation on mechanical and physical properties of recycled aggregate concrete (RAC) with and without silica fume. Constr. Build. Mater. 2014, 61, 50-59. [CrossRef]

20. Silva, R.V.; de Brito, J.; Dhir, R.K. Properties and composition of recycled aggregates from construction and demolition waste suitable for concrete production. Constr. Build. Mater. 2014, 65, 201-217. [CrossRef]

21. Tam, V.W.Y.; Tam, C.M.; Le, K.N. Removal of cement mortar remains from recycled aggregate using pre-soaking approaches. Resour. Conserv. Recycl. 2007, 50, 82-101. [CrossRef]

22. Kim, Y.; Hanif, A.; Usman, M.; Park, W. Influence of bonded mortar of recycled concrete aggregates on interfacial characteristics-Porosity assessment based on pore segmentation from backscattered electron image analysis. Constr. Build. Mater. 2019, 212, 149-163. [CrossRef]

23. Akbarnezhad, A.; Ong, K.C.G.G.; Zhang, M.H.; Tam, C.T.; Foo, T.W.J.J. Microwave-assisted beneficiation of recycled concrete aggregates. Constr. Build. Mater. 2011, 25, 3469-3479. [CrossRef]

24. Kim, Y.; Hanif, A.; Kazmi, S.M.S.; Munir, M.J.; Park, C. Properties enhancement of recycled aggregate concrete through pretreatment of coarse aggregates-Comparative assessment of assorted techniques. J. Clean. Prod. 2018, 191, 339-349. [CrossRef]

25. Kou, S.C.; Poon, C.S. Properties of concrete prepared with PVA-impregnated recycled concrete aggregates. Cem. Concr. Compos. 2010, 32, 649-654. [CrossRef]

26. Kou, S.; Poon, C. Effect of the quality of parent concrete on the properties of high performance recycled aggregate concrete. Constr. Build. Mater. 2015, 77, 501-508. [CrossRef]

27. Behera, M.; Bhattacharyya, S.K.; Minocha, A.K.; Deoliya, R.; Maiti, S. Recycled aggregate from C\&D waste \& its use in concrete-A breakthrough towards sustainability in construction sector: A review. Constr. Build. Mater. 2014, 68, 501-516.

28. Saberian, M.; Li, J.; Nguyen, B.; Wang, G. Permanent deformation behaviour of pavement base and subbase containing recycle concrete aggregate, coarse and fine crumb rubber. Constr. Build. Mater. 2018, 178, 51-58. [CrossRef]

29. Abdel-Hay, A.S. Properties of recycled concrete aggregate under different curing conditions. HBRC J. 2017, 13, 271-276. [CrossRef]

30. Bo, W.; Yong, Y.; Zhao, X.-Y. Residual mechanical properties of compound concrete containing demolished concrete lumps after exposure to high temperatures. Fire Saf. J. 2019, 105, 62-78.

31. Bo, W.; Hemao, J. Compressive fatigue behavior of compound concrete containing demolished concrete lumps. Constr. Build. Mater. 2019, 210, 140-156.

32. Hadavand, B.; Imaninasab, R. Assessing the infuence of construction and demolition waste materials on workability and mechanical properties of concrete using statistical analysis. Innov. Infrastruct. Solut. 2019, 4, 29. [CrossRef]

33. Gupta, N.; Kluge, M.; Chadik, P.; Townsend, T. Recycled concrete aggregate as road base: Leaching constituents and neutralization by soil Interactions and dilution. Waste Manag. 2018, 72, 354-361. [CrossRef]

34. Arulrajah, A.; Disfani, M.; Horpibulsuk, S.; Suksiripattanapong, C.; Prongmanee, N. Physical properties and shear strength responses of recycled construction and demolition materials in unbound pavement base/subbase applications. Constr. Build. Mater. 2014, 58, 245-257. [CrossRef]

35. Arshad, M.; Ahmed, M. Potential use of reclaimed asphalt pavement and recycled concrete aggregate in base/subbase layers of flexible pavements. Constr. Build. Mater. 2017, 151, 83-97. [CrossRef]

36. Ahmed, E.; El-Maaty, B. Utilization of cement treated recycled concrete aggregates as base or subbase layer in Egypt. Ain Shams Eng. J. 2013, 4, 661-673. 
37. Directive 2014/52/EU of the European Parliament and of the Council of 16 April 2014 amending Directive 2011/92/EU on the assessment of the effects of certain public and private projects on the environment. Available online: https://eur-lex.europa.eu/legal-content/EN/TXT/?uri=celex\%3A32014L0052 (accessed on 3 June 2019).

38. Directive 2001/42/EC of the European Parliament and of the Council of 27 June 2001 on the assessment of the effects of certain plans and programs on the environment (OJ L 197, 21.7.2001, p.30). Available online: https://eur-lex.europa.eu/legal-content/EN/TXT/?uri=CELEX:32001L0042 (accessed on 3 June 2019).

39. Spanish Law 21/2013 of December 9 of environmental impact assessment. Available online: https://www.boe. es/eli/es/1/2013/12/09/21/con (accessed on 3 June 2019).

(C) 2019 by the authors. Licensee MDPI, Basel, Switzerland. This article is an open access article distributed under the terms and conditions of the Creative Commons Attribution (CC BY) license (http://creativecommons.org/licenses/by/4.0/). 